\section{Nuffield Foundation Support for Research in Rheumatism}

DURING the past five years the Nuffield Foundation has been supporting much chemical and other work on adrenal hormones, but, with the gradual fading of the original hopes of cortisone and adrenocorticotrophic hormone as panaceas for the chronic rheumatic diseases, the Foundation is now reverting to its original policy of supporting fundamental and clinical research into the nature of the rheumatic diseases. As in the past, this programme will be supported both from the resources of the Oliver Bird Fund, which was created in 1948 by the gift of $£ 450,000$ from Captain Olivei Bird, and from the Foundation's original Nuffield endowment. Two large grants and two smaller ones are being made. Tho Foundation has made a grant of $£ 70,000$ to the University of Manchester, payablo over the next eight years, to extend the work of the rheumatism centre under the director, Prof. J. H. Kellgren, professor of rheumatology in the University. This will be an addition to the original grant of $£ 100,000$, spread over ten years, which was made in 1946 to establish a pioneer centre in Manchester of the kind advocated by an expert medical advisory committee of the Ministry of Health at the end of the Second World War. For the past five years the Foundation has been supporting, with general grants for research staff, the clinical and fundamental work of the rheumatic unit directed by Dr. J. J. R. Duthie, senior lecturer in the Department of Medicine, University of Edinburgh. This unit, sponsored by the University to promote teaching and research in chronic rheumatism and to improve standards of treatment, was opened in the Northern General Hospital in October 1947. Limited accommodation has always been a handicap, and a new building is being erected on a site adjoining the unit's ward at the Northern General Hospital. This building, which will be associated with the name of Captain Oliver Bird, will have consulting and research rooms, clinies and laboratories. $£ 27,000$ has been given to meet the cost of the building and its furnishing, and in addition, the Foundation will continue its annual grant to assist the unit's work, $£ 38,000$ over the five years 1954-58 being provided for this purpose. The two smaller grants are as follows: $£ 8,000$ to the University of Sheffield to finance a research fellowship in the Sheffield Centre for the Investigation and Treatment of Rheumatic Diseases, directed by Dr. H. F. West; and $£ 6,000$ to the Oxford Regional Hospital Board for an experimental pathologist to work under Dr. A. G. S. Hill on the pathogenesis of rheumatic diseases at the Rheumatic Diseases Research Centre at Stoke Mandeville Hospital.

\section{Hungarian Scientific Exchanges}

IN September 1953, when the Hungarian Federation of Scientific and Technical Societies acted as host in Budapest at the Third Assembly of the World Federation of Scientific Workers, it was announced that it was intended that scientists from Western countries should be invited to Hungary in future years. This proposal was, in fact, carried out this year. Ten British and French scientists were invited to spend three weeks in Hungary, partly at the holiday resort on Lake Balaton and the rest of the time in visiting scientific institutes. Altogether, some one hundred and thirty individual visits were made, and every facility was given for the visitors to meet those working in their own fields of research. The visitors gave seventeen lectures to various sections of the Hungarian Federation. It is intended that invitations shall be extended to Hungarian scientists to visit Great Britain and France during the summer of 1955 , so that the initiative of the Hungarian Federation in attempting to improve communication between scientists in the West and the East shall be followed up and, if possible, improved upon. Members of learned societies who might be interested in such exchanges should write to the Secretary-General of the World Federation of Scientific Workers, 15 Half Moon Street, London, W.1.

\section{Rust Infection Studies}

AN important study of the infectivity of singlespore strains, that is, physiological races, of the brown rust fungus (belonging to the group species Puccinia dispersa) to brome grasses, undertaken during a period of fourteen years, has now been reported on by J. Bean, P. W. Brian and F. T. Brooks (Ann. Bot., N.S., 18, 129; 1954). Each rust strain was maintained as a stock culture on a suitable host, kept permanently under 'Cellophane' covers to prevent contamination. The method of inoculation and techniques used to prevent cross-infection are described. By their infection reactions on a represontative selection of Bromus spp. at least five physiological races have been characterized. Two of these have host-ranges confined to a single section of the genus, but others have a much wider host-range within the genus. The uredospore stage of all was identical. Studies of the teleutospores have been limited and knowledge of the species of rust involved is incomplete. All belong to the group-species Puccinia dispersa Erikss. and Henn.; the species $P$. bromina Erikss. and $P$. symphytibromorum Müller were included among the cultures studied, possibly also $P$. bromi-maximi Guyot. In a large series of inoculations, over a period of in all fourteen years, all physiological races have been remarkably stable in their infection types and host-range, and no confirmation of Marshall Ward's 'bridging-host' theory has been obtained. Cultivation of two physiological races for 164 generations on Bromus arduennensis, a species considered by Ward to have special significance as a bridging-host, induced no changes in their host-range.

\section{Engineering Study of the Southern Californian Earthquakes}

A DETAILED study of damage to buildings and other structures caused by the earthquake of July 21 , 1952, has been published by the Seismological Society of America under the title of "An Engineering Study of the Southern Californian Earthquake of July 21, 1952, and its Aftershocks", by Karl V. Steinbrugge and Donald F. Moran (Bull. Seis. Soc. Amer., 44, No. 2B, 199 (April 1954). 2 dollars). The earthquakes, with the number of shocks shown in brackets, occurred on the following days: July 21 (7), 22 (2), $23(3), 25(3), 29$ (2), 31 (1), and August 1 (1) and 22 (1), 1952. A further shock occurred on January 12, 1954. The epicentre of the first shock was at Wheeler Ridge, lat. $35^{\circ} 00^{\prime}$ N., long. $119^{\circ} 02^{\prime}$ W., and its magnitude was $7 \cdot 6$. The aftershocks, of lesser magnitude, were a little to the north and east of the first shock, in Kern County. The study includes sections on damage to structures, schools, dams, roads and bridges, and the earthquake effects on oil production and agriculture. Appendixes detail effects on particular buildings, such as Brock's 